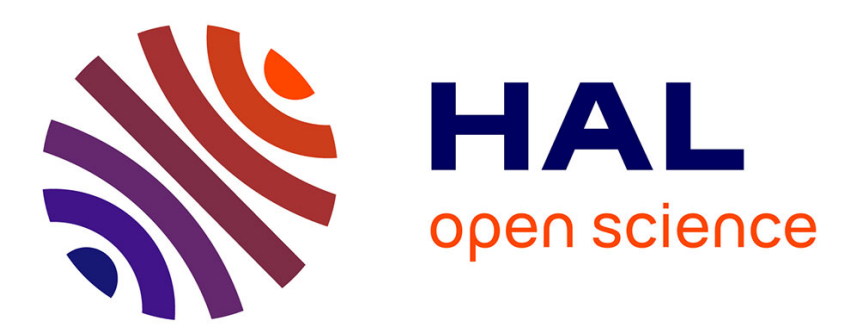

\title{
Shaped Parallel-Plate Lens for Mechanical Wide-Angle Beam Steering
}

T. Strober, S. Tubau, E. Girard, H. Legay, G. Goussetis, Mauro Ettorre

\section{To cite this version:}

T. Strober, S. Tubau, E. Girard, H. Legay, G. Goussetis, et al.. Shaped Parallel-Plate Lens for Mechanical Wide-Angle Beam Steering. IEEE Transactions on Antennas and Propagation, 2021, 69 (12), pp.8158-8169. 10.1109/TAP.2021.3090789 . hal-03480254

\section{HAL Id: hal-03480254 https://hal.science/hal-03480254}

Submitted on 15 Dec 2021

HAL is a multi-disciplinary open access archive for the deposit and dissemination of scientific research documents, whether they are published or not. The documents may come from teaching and research institutions in France or abroad, or from public or private research centers.
L'archive ouverte pluridisciplinaire HAL, est destinée au dépôt et à la diffusion de documents scientifiques de niveau recherche, publiés ou non, émanant des établissements d'enseignement et de recherche français ou étrangers, des laboratoires publics ou privés. 


\title{
Shaped Parallel-Plate Lens for Mechanical Wide-Angle Beam Steering
}

\author{
Thomas Ströber, Ségolène Tubau, Etienne Girard, Hervé Legay, \\ George Goussetis Senior Member, IEEE, and Mauro Ettorre, Senior Member, IEEE
}

\begin{abstract}
This paper presents a parallel-plate lens beamformer for continuous wide-angle scanning. The design is based on a compact dual-lens system with extended scanning range and is optimized using a previously developed geometrical optics technique. Beam steering is accomplished with a mechanical feed system based on the non-contact characteristic of groove gap waveguides, offering large bandwidth, low profile, and mechanical ruggedness. The proposed concept is validated by an all-metal prototype of a $20.5-\lambda$ lens operating in the uplink Ka-band allocated to satellite communications $(27.5-31 \mathrm{GHz})$. Good agreement is obtained between the simulated and measured performance. The measured return loss is greater than $12 \mathrm{~dB}$ over the entire frequency band and beyond. High scanning performances are achieved over an angular range of $\pm 50^{\circ}( \pm 14$ beamwidths), with maximum scan losses in the order of $3 \mathrm{~dB}$ and good pattern stability over the entire band. The proposed solution is particularly suited for next-generation satellite terminals requiring compact broadband antennas with continuous beam steering capability over a large angular range.
\end{abstract}

Index Terms-beam-scanning antennas, gap waveguide technology, lens antennas, mechanical beam scanning, parallel-plate optics.

\section{INTRODUCTION}

The evolution of low and medium earth orbit satellite constellations for ubiquitous high-speed coverage has driven the development of low-cost antenna solutions with large angular scanning range. In this context, continuous parallelplate beamformers have received particular attention [1]-[4]. Their main advantages include broadband performance, mechanical ruggedness, high radiation efficiency and ease of manufacturing. Especially the latter two aspects are important factors in applications where a high number of beams or large apertures are required. For moderate scan ranges (up to about $35 \% 10$ beamwidths), the parabolic pillbox presents an attractive solution [2], [5]. Beyond this range, the performance is typically limited by the onset of high sidelobes on the boresight side. Wide-angle scanning up to $\pm 55^{\circ}$ has been demonstrated with circular pillbox antennas [6]. However, additional optics are essential to correct spherical aberrations and to provide acceptable levels of aperture efficiency. Luneburg

Manuscript submitted -/-/2020.This work was supported by the European Commission under H2020 project REVOLVE (MSCA-ITN-2016-722840).

T. Ströber and M. Ettorre are with the Institut d'Electronique et de Télécommunications de Rennes, UMR CNRS 6164, Université de Rennes 1, 35042 Rennes, France (e-mail: thomas.strober@univ-rennes1.fr; mauro.ettorre@univ-rennes1.fr).

S. Tubau, E. Girard and H. Legay are with the Research and Development Department, Thales Alenia Space, 31037 Toulouse, France.

G. Goussetis is with the Institute of Sensors, Signals and Systems, HeriotWatt University, EH14 4AS Edinburgh, United Kingdom. lenses offer aberration-free scanning and a number of parallelplate implementations with low fabrication complexity have been proposed to date [1], [7], [8]. More recently, a novel type of geodesic lens has been proposed for scan ranges beyond $\pm 60^{\circ}$ [4], [9]. The described approach allows wideband operation, relatively simple construction and a significant reduction in height when compared to the original Rinehart-Luneburg design. However, the overall size and shape of the lens limit its range of applications. Furthermore, lenses based on a shaped vertical parallel-plate waveguide (PPW) section have been introduced recently [3], [10]. The degrees of freedom of previously presented designs are comparable to that of conventional bifocal lenses [11], thus yielding excellent focusing performance over a moderate scanning range. Just as geodesic lenses, such designs overcome the bandwidth limitation and manufacturing complexity of constrained lenses. In addition, the proposed solution does not require an oversized aperture and offers a high degree of design flexibility, such that the lens geometry can be formed to fit into various beamforming structures. Due to its rectangular footprint, the lens can be combined with advanced linear radiating structures such as continuous transverse stub arrays [2].

In previous parallel-plate lens designs stationary feeds are employed to provide multiple fixed beams or discrete beam scanning. The proof-of-concept design presented in [10] produces six equally spaced beams in the range $\pm 30^{\circ}$. Improved multiple-beam coverage of a similar angular range has been demonstrated with a Ka-band design [3]. To provide nearconstant communication links, future satellite constellations with highly dynamic link geometries call for continuous beam scanning over an enhanced angular range of up to $60^{\circ}$. These two essential requirements have not been addressed in the context of shaped PPW lenses with linear aperture.

For ground-segment antennas, continuous scanning is most conveniently accomplished by mechanical movement of a smaller subcomponent. Movable feeds with coaxial cables have been employed in beam-scanning pillbox systems [2], [12]. For lens antennas with circular feed motion path, rotary waveguide joints are most commonly used to design mechanical scanning feeds [13]. Both solutions involve a number of disadvantages such as low impedance bandwidth, the susceptibility to mechanical stress for coaxial-to-waveguide transitions, and the vertical feed-through geometry of rotary joints. In the past decade, the design flexibility of gap waveguides has promoted the development of various highperformance antennas and circuit components for millimeterwave applications. Gap waveguides combine the advantages of 
conventional waveguides such as high power-handling capability and low loss with the unique feature that no physical contact is needed between the two waveguide plates [14]. So far, this characteristic has been of interest mainly for manufacturing reasons, since high-precision machining and assembly can be avoided and the associated costs therefore be reduced significantly [15]. Moreover, the concept of gap waveguides has been exploited for the design of rotary phase shifters enabling mechanical beam scanning with slot arrays [16], [17].

In this paper, two recent advances in the development of continuous parallel-plate beamformers are presented: first, the design of a dual-lens system with enhanced scanning performance is introduced. The solution proposed here uses a pair of closely spaced converging PPW lenses [3], [10] resulting in a compact design with large $F / D$ optics. Second, a novel mechanically reconfigurable feed system based on gap waveguide technology is presented. By moving one plate of the gap waveguide feed along the focal arc of the lens system, the main beam is mechanically steered in elevation.

This paper is organized as follows. In Section II, basic design principles for the quasi-optical system are discussed, while emphasis is placed on the involved design trade-offs due to mechanical constraints. The design of the feed system is detailed in Section III. Simulation and measurement results are reported in Section IV for a lens beamformer operating at Ka-band. Concluding remarks are given in Section V.

\section{QUASI-OptiCAL DESIGN}

\section{A. Basic Design Principles}

Fig. 1 shows the basic geometry of a parallel-plate lens beamformer. The structure can be divided into two main parts: a horizontal parallel-plate cavity forming the focal region and a continuously shaped vertical PPW section which constitutes the actual lens (inverted U-shape in cross section). Throughout the design, the plate spacing $H$ is chosen such that only the dominant transverse-electromagnetic (TEM) mode propagates. A linear flare is used to interface the parallel-plate region with free space.

A deeper insight into the focusing behavior of the structure can be gained by approximating it as a constrained lens, allowing the definition of two independent path length conditions. Since the delay section is formed by a uniform guide, the continuous lens can be viewed as the "constant refractive index" design discussed in [11], with the difference that inner and outer lens profile are identical and, in theory, collocated. The latter property is also the key difference with respect to the classical Rotman lens where the inner lens contour and the array port positions can be defined independently. It should be noted that also the proposed design is a true-time delay device, offering frequency-invariant beamforming.

Following the design principles in [11], two symmetrical off-axis focal points can be specified, which leads to elliptical lens profiles. Furthermore, a simple expression describing the height profile of the vertical parallel-plate section can be obtained. Nevertheless, previous work has shown that the constrained lens model is not entirely adequate for the analysis

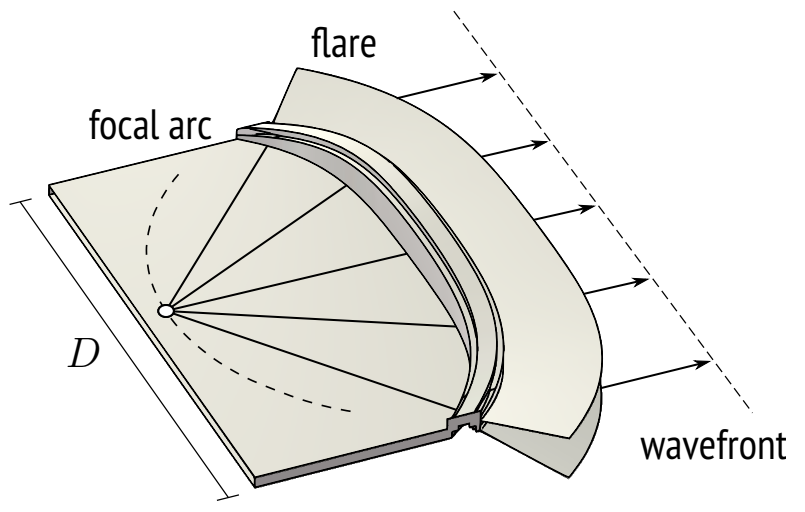

(a)

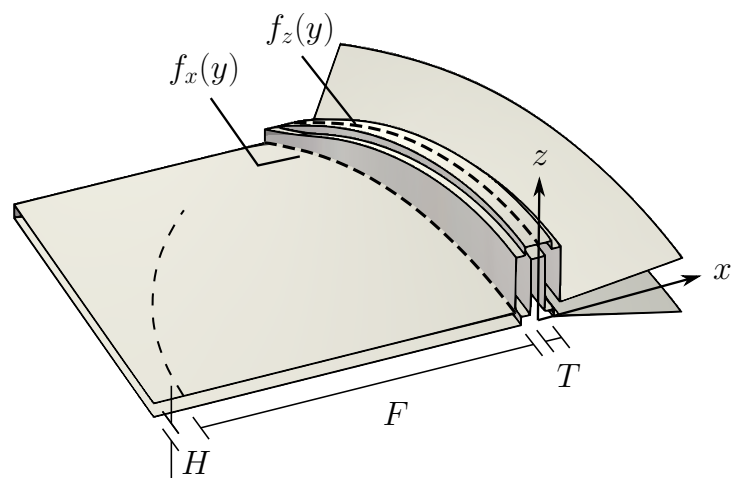

(b)

Fig. 1: (a) Perspective view and (b) cross-sectional view of a continuous parallel-plate lens.

and design of shaped PPW lenses as it only approximates the propagation inside the vertical section. A ray-tracing procedure has been developed [18] to account for this effect, thus allowing an accurate prediction of the resulting radiation patterns. Moreover, due to its low computational cost, this method can be conveniently embedded into an optimization process. In this case, it is advantageous to represent the lens profiles by polynomial functions which provide additional degrees of freedom for retrieving the performance of the constrained lens model. The optimization procedure can be based on a phase-only model with the goal to minimize the root-meansquare (RMS) phase error for a range of feed positions. This approach results most likely in a non-focal design [19] which can differ considerably from the bifocal geometry. Using instead a pattern-based optimization, the available degrees of freedom can be further exploited to also control the amplitude performance of the lens [3].

In selecting the lens diameter $D$ and a reference focal ratio $F / D$, the desired beamwidth, edge taper, size limitations and the requirements on scan loss and sidelobe levels need to be taken into account. The constrained lens model, for which the primary aberrations can be found explicitly [11], aids in the dimensioning process. Fig. 2 shows the maximum phase error at the edge of a $20-\lambda$ aperture that occurs within a certain angular scanning range for a given focal ratio. As in [11], the presented results were calculated assuming that the focal point angular position $\alpha$ is set according to the maximum scanning 


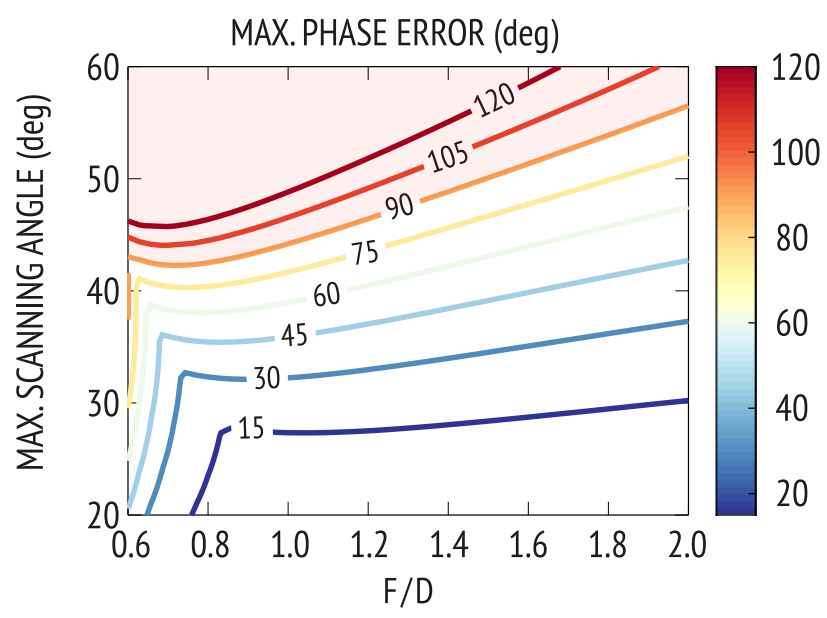

Fig. 2: Maximum phase error at the aperture edge of an equivalent constrained lens of $D=20 \lambda$ with refocused focal arc as a function of $F / D$ and scanning range.

angle. The refocused configuration refers to a focal arc defined by $g=1+\alpha^{2}$, with $g$ being the ratio of on-axis feed distance to focal length. It can be seen that the lens is well corrected up to scan angles of about $40^{\circ}$ for a moderate $F / D$ of 0.7 . Higher variations are seen for lower focal ratios, i.e., where the approximations made in [11] for deriving the refocusing condition become less accurate. In this simplified model, the phase error is predominantly coma, resulting in a sidelobe level of about $-13 \mathrm{~dB}$ for a $90^{\circ}$-error at the aperture edge when employing a 10-dB edge taper. It has been demonstrated in [3] and [20], that a similar correction can be achieved for practical parallel-plate designs by shaping the lens profiles and feed curve.

Next, starting points and limits for the coefficients $a_{n}$ in the polynomials representing the inner lens and delay path profile (see Fig. 1)

$$
\begin{aligned}
& f_{x}(y)=\sum_{n=0}^{N} a_{n}^{x} y^{2 n} \\
& f_{z}(y)=\sum_{n=0}^{N} a_{n}^{z} y^{2 n}-\min \left\{\sum_{n=0}^{N} a_{n}^{z} y^{2 n}\right\} .
\end{aligned}
$$

need to be defined. The above expressions refer to polynomials of order $2 N$ defined over the normalized range $-d / 2 \leqslant y \leqslant d / 2$ with $d=D / F$. The initial values can be set such that $\left(f_{x}\right.$, $f_{z}$ ) approximate the shape of an adequate constrained lens model with elliptical profiles. The parameter range should be specified such that strongly curved contours, where the raytracing method based on local application of Snell's law of reflection becomes inaccurate, are avoided.

While the above guidelines are applicable to various lens designs, the parameters defining the feed positions require more careful consideration. In the classical constrained lens designs, feeds are employed on a circular curve [11], [21]. Moreover, it has been demonstrated in [22] and [23] that phase errors for non-focal feed positions can be reduced significantly when resorting to non-canonical feed curves. Accordingly, the feed position for each scan angle could be used as an additional

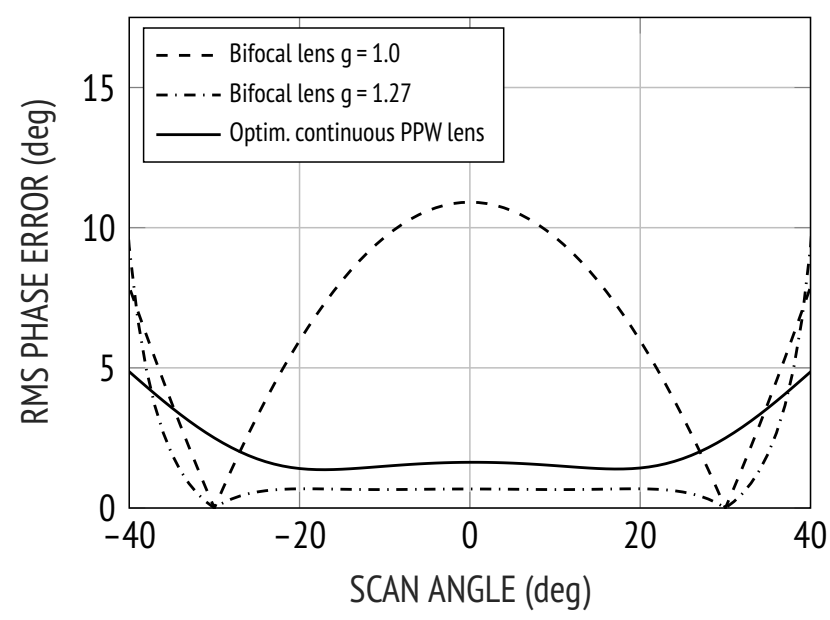

Fig. 3: Normalized RMS phase error versus scan angle of constrained bifocal lens models and of an optimized non-focal design with $F / D=0.7$.

degree of freedom in the optimization process. However, using a circular feed motion path substantially reduces the complexity of the mechanical design since a simple rotary actuator can be used to displace the feed. Another design constraint is the fact that at every scan position, the feed should be directed toward the center of the lens to ensure symmetric illumination and a minimum of spillover losses. This is particularly important if no absorbing sidewalls or dummy ports are used since internal reflections may lead to disturbed radiation patterns and increased reflection losses. Unless an additional actuator is used, a proper orientation of the feed is only achieved if the center of the focal arc coincides with the apex of the inner lens profile. As a results, only one parameter, namely, the radius of the focal arc can be used in the optimization process for defining the feed positions.

The impact of the above design constraints can be demonstrated by studying the RMS phase errors of a constrained lens reference model. The results plotted in Fig. 3 are normalized by $F / \lambda$ and refer to a bifocal lens with $F / D=0.7$ and focal point angular positions of $\alpha= \pm 30^{\circ}$. As already indicated earlier, significant phase errors occur for the required configuration of $g=1.0$ (focal arc centered at the apex of the lens) at broadside. The effect of refocusing is verified by the low RMS error resulting for $g=1.27$; however, this configuration is only relevant for stationary feed systems. It should be also noted that the curvature of the resulting focal arc is more pronounced, which may lead to practical difficulties [22]. Also shown in Fig. 3 is the RMS error of an optimized continuous PPW lens having the focal arc centered on the apex of the inner lens contour. The results, calculated using the ray-tracing technique detailed in [18], confirm that for scan angles up to $30^{\circ}$, a low, nearly constant level of phase errors can be achieved with such a non-focal design.

\section{B. Dual-Lens Design}

As indicated in Fig. 3, the focusing performance for each lens model deteriorates rapidly at scan angles beyond $\pm 35^{\circ}$. 


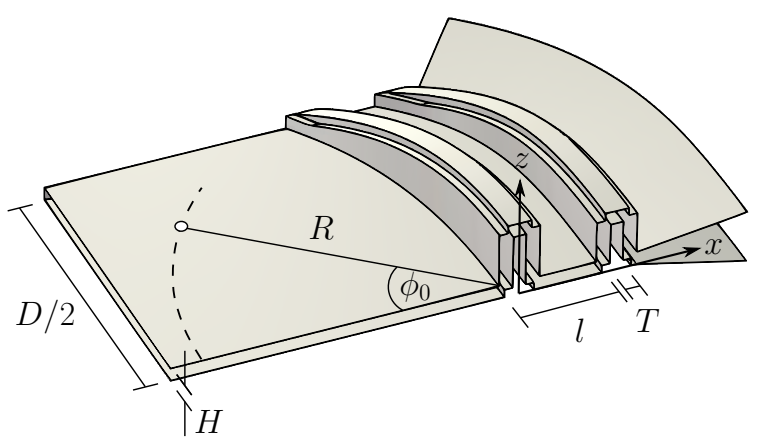

(a)

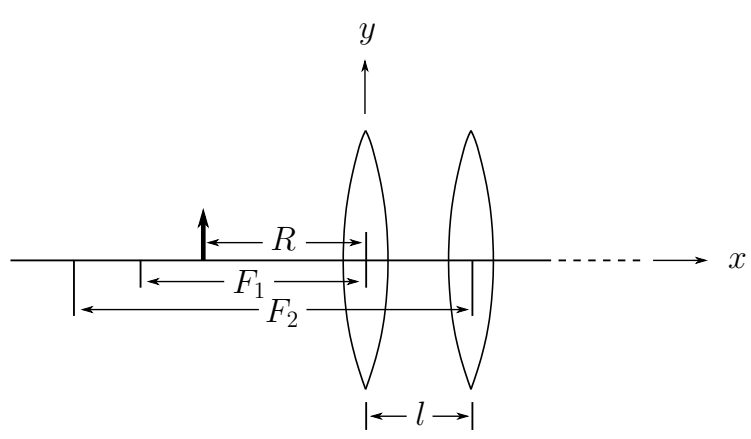

(b)

Fig. 4: (a) Cross-sectional view of a dual-lens system, (b) firstorder optics model.

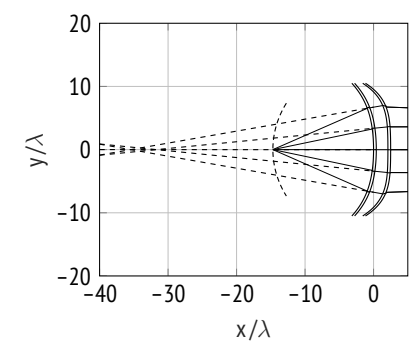

(a)

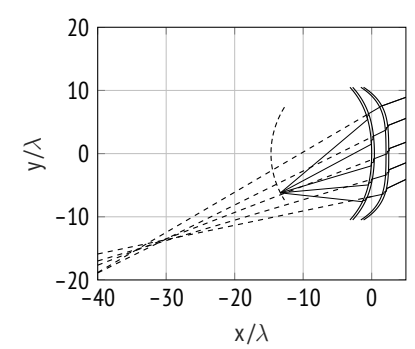

(b)
Fig. 5: Rays passing through a dual-lens system in transmission (-) and rays describing the virtual image formation (- -) for (a) $\phi_{0}=0^{\circ}$, (b) $\phi_{0}=25^{\circ}$.

Naturally, this effect can be mitigated by increasing the focal length of the lens. Referring to the bifocal lens model, it can be shown that second-order aberrations decrease as $1 / F$ and coma errors as $1 / F^{2}$ [11]. For the desired scan range of $\pm 50^{\circ}$ it appears that, unless an excessive edge taper is used, a focal ratio greater than unity is required in order to keep sidelobe levels and scan losses within reasonable limits. This would, in turn, necessitate a more directive feed to maintain a given edge illumination. In fact, there is no restriction on the size of the feed aperture in the proposed single-feed design. However, the axial extent of the lens and the support required for the feed system become unreasonably large in such a design.

Instead, a second lens of equal diameter is introduced to provide additional degrees of freedom. The resulting structure can be treated as a system of two thin lenses as shown in Fig. 4(b). The basic design principle consists in using two

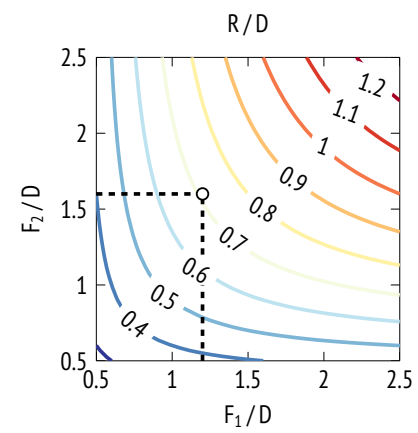

(a)

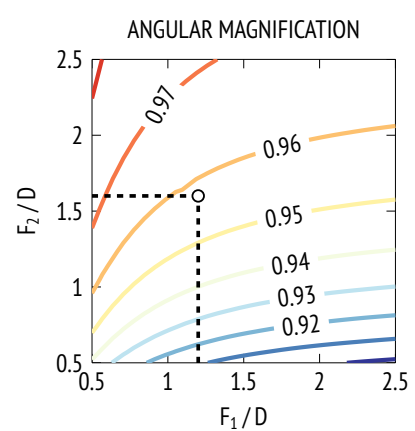

(b)
Fig. 6: (a) Effective focal length and (b) angular magnification of a dual-lens system with $l=D / 10$.

converging lenses of larger focal ratios $F_{1} / D$ and $F_{2} / D$ which, with a proper spacing $l$, yield a moderate effective focal ratio $R / D$ representing the radius of the feed arc. Since on transmit, the feed is placed at a distance $R<F_{1}$ from the origin, i.e., in between the first lens and its focal point, a virtual image is formed as illustrated in Fig. 5 for two different feed angular positions $\phi_{0}$. To transform the fields generated by the feed into a plane wave, the second lens is designed such that its focal surface (described by $F_{2}$ at broadside) coincides most effectively with the virtual image positions.

The design frequency is fixed to $f_{\mathrm{c}}=29.25 \mathrm{GHz}$ with a free-space wavelength of $\lambda_{0}=10.3 \mathrm{~mm}$. Targeting a beamwidth similar to the design in [3], a lens diameter of $D=20.5 \lambda_{0}=210 \mathrm{~mm}$ is selected. The design procedure for the dual-lens system consists of three steps. First, the basic parameters $F_{1}, F_{2}, R$ and $l$ are defined using first-order optics [24]. In the present case, the lens spacing is set to $l=2 \lambda_{0} \approx D / 10$. This leads to a compact design while providing some margin for the accommodation of the lens profiles $f_{x}$ in the $x y$ plane, which may exhibit different curvatures at the edges. In addition, good accessibility during machining is ensured. The effective focal ratio $R / D$ of the system is shown in Fig. 6(a) as a function of the focal ratios of the two individual lenses. Furthermore, Fig. 6(b) shows the estimated angular magnification for a feed displaced by $D / 2$ along the focal plane, i.e., the ratio between beam pointing angle and angular feed displacement. Also in this case, a trade-off must be found between limited phase errors (large $F_{1}$ and $F_{2}$ ) and compact size (small $R / D$ ). A lower limit on the focal ratios can be infered from Fig. 2 . Additionally, the reduction in field of view must be considered. It should be noted that in the limit as $l \rightarrow 0$, the magnification approaches unity for all lens combinations. In the final design, focal ratios of $F_{1} / D=1.2$ and $F_{2} / D=1.6$ are used, resulting in a moderate effective focal ratio of $R / D=0.7$ and an angular magnification of about 0.96 .

Starting from analytically defined surfaces [18], a fast phase-only optimization process is used to shape the contours of both lenses separately. Even-order polynomials of order ten are used to define a lens geometry as shown in Fig. 5. Finally, the dual-lens system is fine-tuned by performing an optimization with respect to the secondary pattern characteristics [20]. 


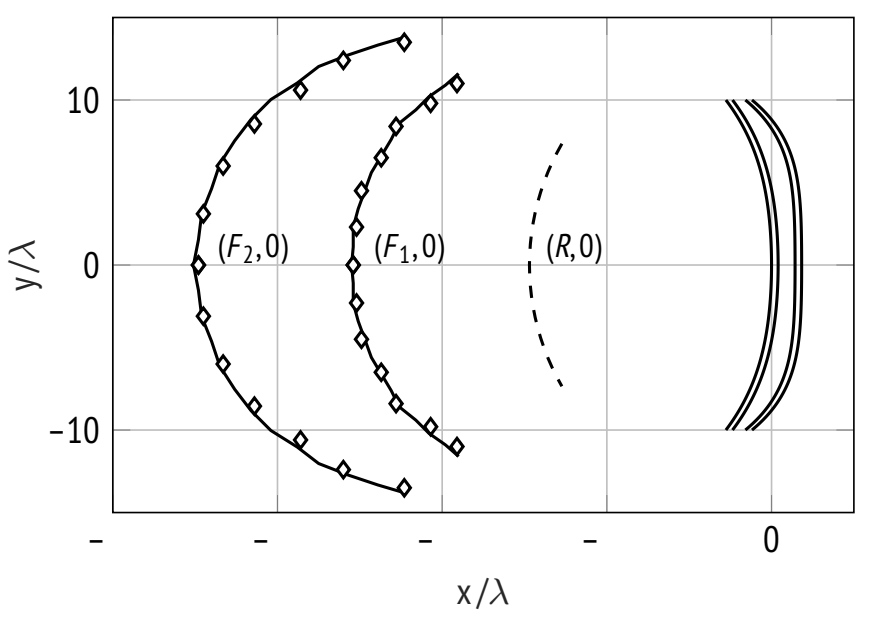

Fig. 7: Calculated (-) and simulated (o) focal surface for an angular range of $\left[0 \ldots 30^{\circ}\right]$, imposed focal arc (- ) .

\section{0} 30 20 10

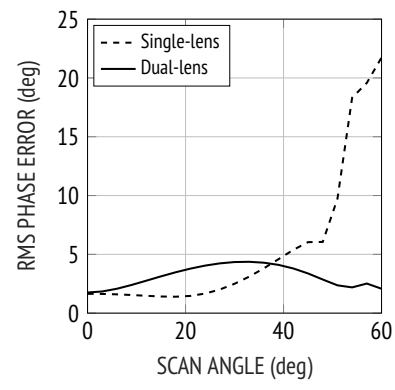

(a)

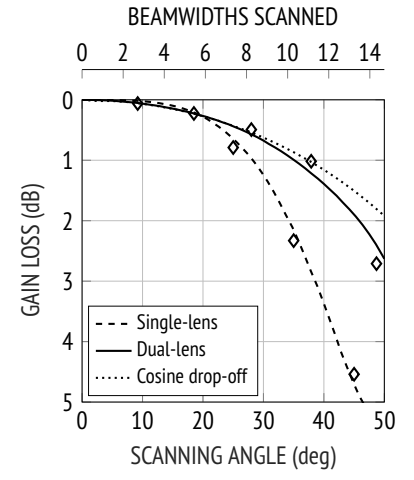

(b)
Fig. 8: (a) Normalized RMS phase error and (b) gain loss versus scan angle of optimized single-lens and dual-lens design for a $20-\mathrm{dB}$ edge taper; simulation results $(\diamond)$.

Although requiring the evaluation of a radiation integral in each iteration, such an approach is essential in the final design stage since amplitude-related effects become critical at large scanning angles. The optimized polynomial coefficients are, in ascending orders, $\boldsymbol{a}^{x_{1}}=[0,-0.23,-0.34,0.06,0,0], \boldsymbol{a}^{z_{1}}=[0$, $-0.118,-0.04,0,0.05,0]$ for the first lens and $\boldsymbol{a}^{x_{2}}=[0$, $0.05,-0.63,-0.18,-0.03,0], \boldsymbol{a}^{z_{2}}=[0,-0.099,0,0.03,0,0]$ for the second lens. The focal surfaces of the two separate lenses resulting from plane-wave incidence at angles in the range $\left[-30 \ldots 30^{\circ}\right]$ are plotted in Fig. 7; for illustration also the lens contours and the imposed feed arc are depicted. The RMS phase error of the final dual-lens design is shown in Fig. 8(a), indicating good performance over the entire scan range. In fact, the curve suggests good focusing performance even up to $60^{\circ}$. However, in this case the feed lies relatively close to the edge of the first lens, resulting in a strongly distorted amplitude distribution over the aperture. Geometrical optics and full-wave simulations showed that no useful patterns can be produced at this angular range.

For validation, the phase of the electric field along a straight line in front of the lens aperture has been extracted from

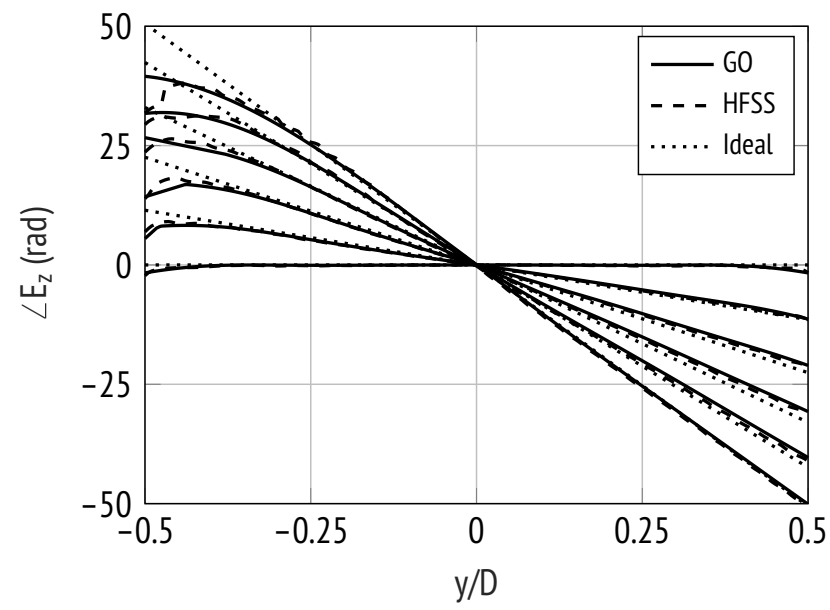

Fig. 9: Calculated, simulated and ideal phase front along a straight line in front of the lens aperture.

full-wave simulations in Ansys HFSS. As can be seen from Fig. 9, a good agreement with the results from ray tracing is found over large parts of the aperture; the ideal phase profile is depicted for comparison. However, for wide scan angles the deviation of the phase front becomes more significant at the aperture edge toward negative $y$ (i.e., on the side where the feed is located). This is due to the limited accuracy of the raytracing method when angles made by incident rays with the normal vectors to the lens contours become large. In this case, the rays inside the vertical delay section experience significant lateral deflection but are still represented by straight lines; a more accurate description would be achieved with geodesic rays [25]. The calculated gain loss is shown in Fig. 8(b) for the optimized single- and dual-lens configuration with linear aperture and an edge taper of $20 \mathrm{~dB}$. It can be seen that the latter provides nearly a cosine variation of gain up to $40^{\circ}$. The estimated scan loss at $50^{\circ}$ is about $2.5 \mathrm{~dB}$.

Up to this point, the performance of the dual-lens has been studied at a fixed frequency. To demonstrate its focusing properties over frequency, the lens system of Fig. 4(a) (without flare) is simulated under plane-wave incidence. The positions of the resulting focal spots are shown in Fig. 10 for a range of incidence angles and frequencies. The high stability of these points with frequency verifies the true time delay of the lens.

\section{Reconfigurable FEed DeSIGN}

\section{A. Gap Waveguide Structure}

For a dynamic beam steering mechanism, a movable connection between external circuits and the feed must to be provided. Coaxial cables are light weight and can track virtually any form of motion, therefore offering great design flexibility. However, even for stationary feeds, precise machining and assembly of the coaxial-to-waveguide transition is required to ensure a proper positioning of the probe [12]. To mitigate the risk associated with recurrent mechanical stress, more rugged feed designs based on rotary joints [13] or other adjustable waveguide systems [26] can be employed. However, the former provide typically narrowband performance [27]-[29]. 


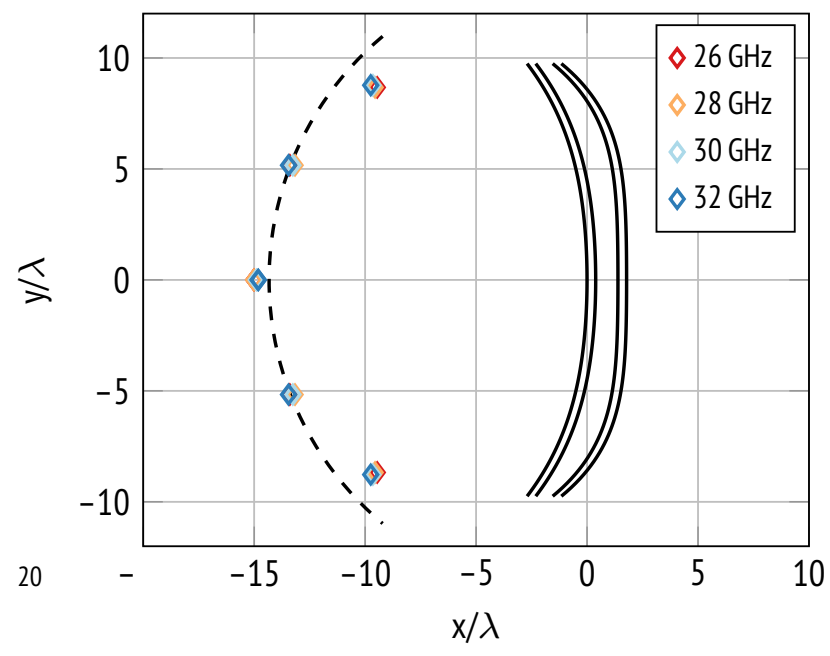

Fig. 10: Simulated focal spot positions for angles of incidence in the range $\left[-40^{\circ},-20^{\circ} . .40^{\circ}\right]$ at different frequencies, imposed focal arc (- -).

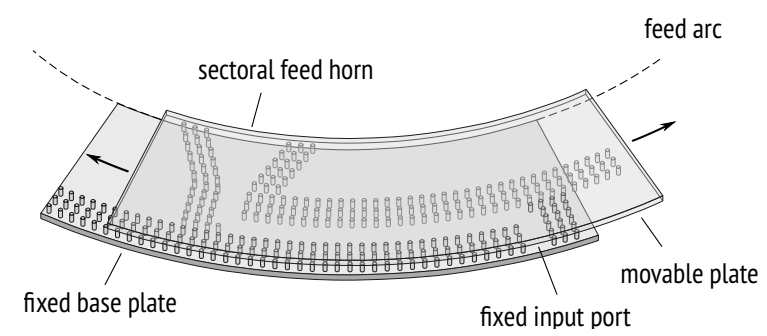

(a)

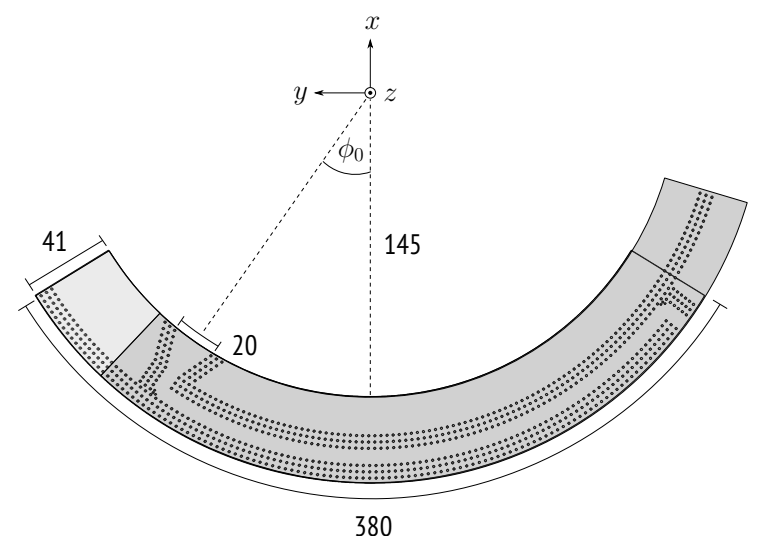

(b)

Fig. 11: (a) Schematic view of groove gap waveguide feed system, (b) top view of the final structure (all dimensions in $\mathrm{mm})$.

Moreover, the vertical feeding from the bottom complicates the integration of such structures into the proposed lens beamformer. It has been found that groove gap waveguides offer a higher degree of freedom for the design thus allowing a low-profile feed system with fixed input port. The resulting feed concept is shown schematically in Fig. 11. As can be seen, the gap waveguide design is based on distributing the textured surface confining the propagating fields on the two physically

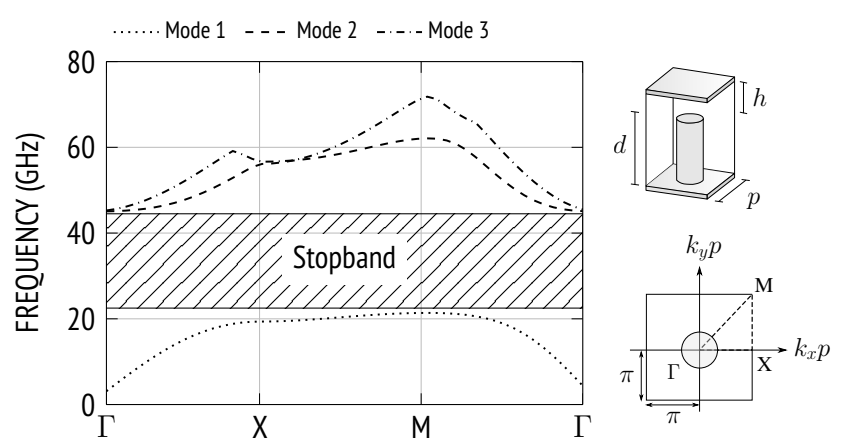

Fig. 12: Dispersion diagram of groove gap waveguide unit cell.

separated plates. The guiding structure is composed of two right-angled $H$-plane bends, a circular section of variable length between these and a sectoral horn. The pins forming the feed horn are found on the upper plate (movable, shown transparent in Fig. 11), while the pins defining the input section are located on the lower plate (stationary).

The bandgap structure, realized by metallic pins, was designed following the guidelines given in [14] for Ka-band operation and optimized using the Eigenmode solver of CST Microwave Studio. Taking into account manufacturing constraints, an air gap of $h=0.5 \mathrm{~mm}$, a pin radius of $r=0.5 \mathrm{~mm}$, a pin height of $d=2.7 \mathrm{~mm}$ and a periodicity of $p=3.0 \mathrm{~mm}$ were selected. The dispersion diagram computed using the CST Eigenmode solver is shown in Fig. 12. A frequency stopband of about one octave is achieved, ranging from 22 to $45 \mathrm{GHz}$. The proposed feed system involves a number of waveguide and gap waveguide discontinuities that largely determine the overall impedance bandwidth of the beamforming device. As indicated in Fig. 11, additional pins were used to realize compensated $H$-plane corners that are free to move. The width of the groove is $7.11 \mathrm{~mm}$, matching the dimensions of a WR28 standard waveguide, from the input to the throat of the sectoral horn. The latter is designed to provide an edge taper of $20 \mathrm{~dB}$. The effective length of the curved gap waveguide (measured along the center of the groove) ranges from $8 \mathrm{~mm}$ $\left(\phi_{0}=50^{\circ}\right)$ to $310 \mathrm{~mm}\left(\phi_{0}=-50^{\circ}\right)$. In the frequency band of interest, the simulated attenuation for a groove gap waveguide in aluminum (alloy $5083 \mathrm{H} 111, \sigma=1.72 \times 10^{7} \mathrm{~S} / \mathrm{m}$ ) varies from $0.015 \mathrm{~dB} / \mathrm{cm}(31 \mathrm{GHz})$ to $0.021 \mathrm{~dB} / \mathrm{cm}(27.5 \mathrm{GHz})$.

\section{B. Non-Contacting Choke Joint}

For feeding the antenna, a standard rectangular waveguide needs to be connected to the groove gap waveguide structure. Since the upper plate of the latter is rotated during scan, a motional joint is required. In fact, additional support structure could be provided to ensure a mechanical decoupling between movable and stationary external waveguide parts. However, a more compact solution is to use a non-contacting flange. Design guidelines and approximate circuit models for conventional choke-flange junctions with circular groove are given in [30]. More recently, waveguide joints based on gap waveguide and glide-symmetric structures have been proposed [15], [31]. Both allow a low-leakage transition, even when no 


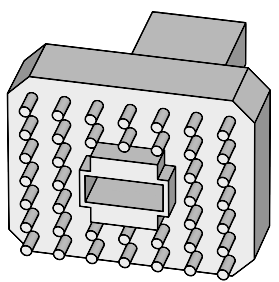

(a)

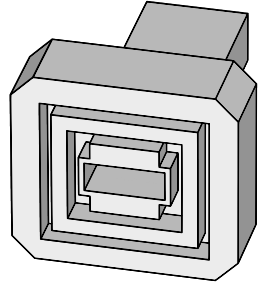

(b)
Fig. 13: Choke flange based on (a) pin bed structure, (b) concentric grooves.
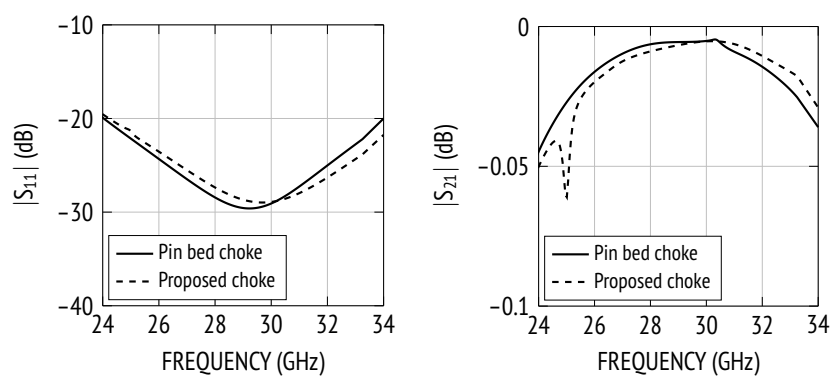

Fig. 14: Simulated $S$-parameters of pin bed choke flange and proposed choke flange for a gap of $\lambda_{0} / 20=0.5 \mathrm{~mm}$.

mechanical contact between the flanges is provided. However, due to the relative motion in the present feed system, only the gap waveguide design is suited for this purpose. As shown in Fig. 13, the rim surrounding the waveguide aperture has been optimized to increase the bandwidth of the quarter-wave transformer. The bandgap structure described in the previous section can be readily reused to create the desired cutoff condition in the radial guide formed by the gap. To reduce manufacturing complexity, the pin bed structure has eventually been replaced by an additional rectangular groove, providing an effective short circuit at the quarter-wavelength point of the inner choke. The position and width of the outer groove need to selected carefully such that no standing waves are formed by the fields excited in the air-gap region [32]. The simulated $S$-parameters of the developed choke flange are shown in Fig. 14. The impedance matching is comparable to that of a conventional choke joint [30]. Moreover, the low insertion loss confirms that the concentric choke structure provides excellent shielding, similar to that provided by the isotropic impedance surface of the gap waveguide design.

\section{EXPERIMENTAL VALIDATION}

\section{A. Manufacturing}

The final structure is shown in Fig. 15. The lens system and radiating aperture are rotated by $90^{\circ}$ compared to the singleridge implementation presented in [33]. A similar configuration would be obtained when using the lens beamformer to excite a parallel-fed continuous transverse stub array. In this way, the problem of aperture blockage by the movable part of the feed system at one edge of the scanning range $\left(\phi_{0} \rightarrow 50^{\circ}\right)$ is avoided as well. The parallel-plate spacing in the lens region is set to $H=2 \mathrm{~mm}$, which is matched to the height of the gap

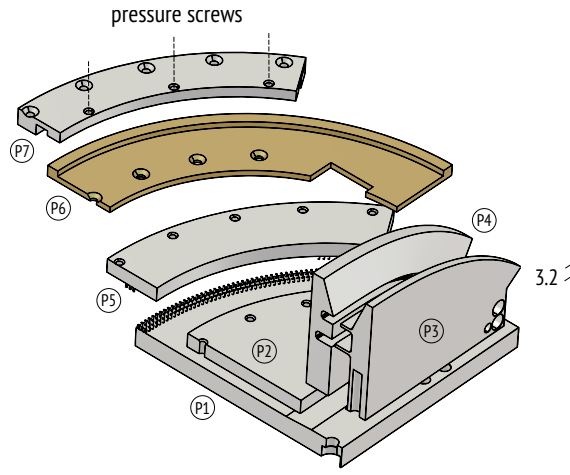

(a)

(c)

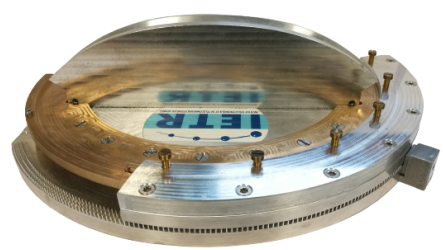

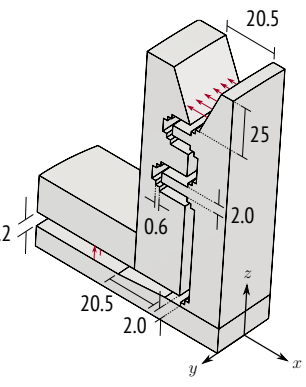

(b)

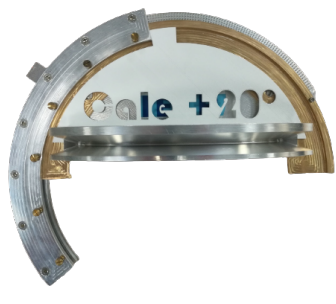

(d)
Fig. 15: (a) Cross-sectional view of the antenna assembly. (b) Slice view of the parallel-plate structure (not to scale, all dimensions in $\mathrm{mm}$ ). (c) Perspective view and (d) top view of all-metal prototype.

waveguide $(d+h=3.2 \mathrm{~mm})$ using a linear taper with a length of $2 \lambda_{0}=20.5 \mathrm{~mm}$. In both regions, the spacing is well below half the wavelength at the maximum frequency of $31 \mathrm{GHz}$ such that only the dominant TEM mode is transmitted to the flare. The thickness of the ridges is $T=2 \mathrm{~mm}$. As indicated in Fig. 15(b), two-step $90^{\circ} \mathrm{E}$-plane bends are used throughout the structure to achieve wideband matching. The simulated return loss of the reduced model of Fig. 15(b) is shown in Fig. 16 and compared with that of the same structure without the additional $90^{\circ}$ bend. This modification has only a small impact on the reflection coefficient, which remains below $15 \mathrm{~dB}$ in the frequency band $27.5-31 \mathrm{GHz}$. Simulations of the entire structure at different scan angles, not reported here for brevity, also confirmed that the radiation patterns remain largely unaffected by the additional bend. Since scanning is demonstrated in the $H$ plane ( $y z$ plane), no efforts have been made to optimize the flare with respect to the pattern in the orthogonal plane. The width of the radiating aperture with respect to $x$ is $2 \lambda_{0}=20.5 \mathrm{~mm}$ and the flare length $25 \mathrm{~mm}$. This is large enough to avoid scattering from the base block, resulting in a symmetric $E$ plane pattern. Further improvement in gain could be obtained using a shaped flare [9].

The prototype was manufactued in several blocks of bare aluminum using a conventional milling process. The focal region is formed by the two horizontal parts $\mathrm{P} 1$ and $\mathrm{P} 2$ shown in Fig. 15(a). As in [3], the lens is made of two complementary blocks, one providing the ridges (P3) and the other one the cavities (P4). The movable feed system corresponds to parts P5 


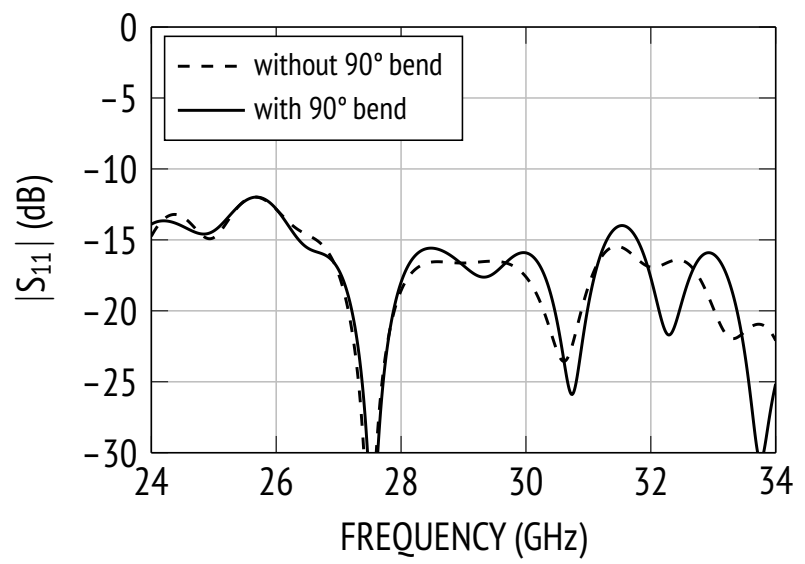

Fig. 16: Simulated input reflection coefficient of the reduced PPW model.

and P7, with the former comprising the sectoral horn. Instead of an additional choke, a bronze bearing (P6) was placed at the transition region between the movable and stationary part, preventing leakage from the finite gap. The bearing material is easy to machine and offers a high resistance to friction and wear. The non-contacting flange was made by $3 \mathrm{D}$ printing. The final structure was assembled by bolting the blocks together.

\section{B. Measurement Results}

The prototype was measured in the compact antenna test range of IETR. Each angular feed position was adjusted using a prefabricated angle gauge as shown in Fig. 15(b). The movable plate was fastened with pressure screws. These also ensure that a proper gap of $h=0.5 \mathrm{~mm}$ is provided along the groove gap waveguide.

The simulated and measured input reflection coefficient are shown in Fig. 17 for a range of feed positions. Simulations predict an $S_{11}$ level around $-20 \mathrm{~dB}$ in the frequency band of interest, with a maximum of $-15 \mathrm{~dB}$. The measured reflection coefficient is somewhat higher, around $-15 \mathrm{~dB}$ with a maximum of $-12 \mathrm{~dB}$. This difference is attributed to fabrication tolerances of the 3D printed choke flange. It can be seen that in both cases, the maximum level of mismatch does not vary significantly with the feed position. As a result, similar results are obtained for feed positions in the range $\phi_{0}<0$. The broadside radiation pattern at the design frequency in the two principal planes is plotted in Fig. 18. A good agreement between measurement and simulation is seen for the main beam and near-in sidelobes. The measured cross polarization levels are below $-35 \mathrm{~dB}$ (peak-to-peak) in both planes. The sidelobe level in the $E$ plane is about $-13 \mathrm{~dB}$, as expected for an untapered distribution.

The $H$-plane radiation patterns are shown in Fig. 19 for all measured feed positions. The results are in very good agreement with simulations in terms of pointing angle, beamwidth and gain loss. At the center frequency, a cosine variation of gain is obtained up to scan angles of $\pm 30^{\circ}$ as in [3]. The measured scan loss is $2.7 \mathrm{~dB}$ and $3.3 \mathrm{~dB}$ for beams pointing at $49^{\circ}$ and $-49^{\circ}$, respectively. This asymmetry is mainly due to

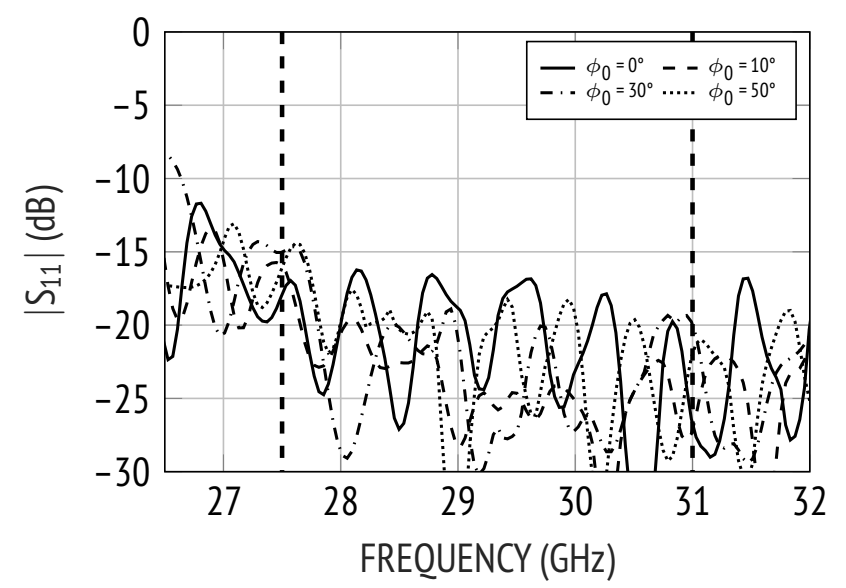

(a)

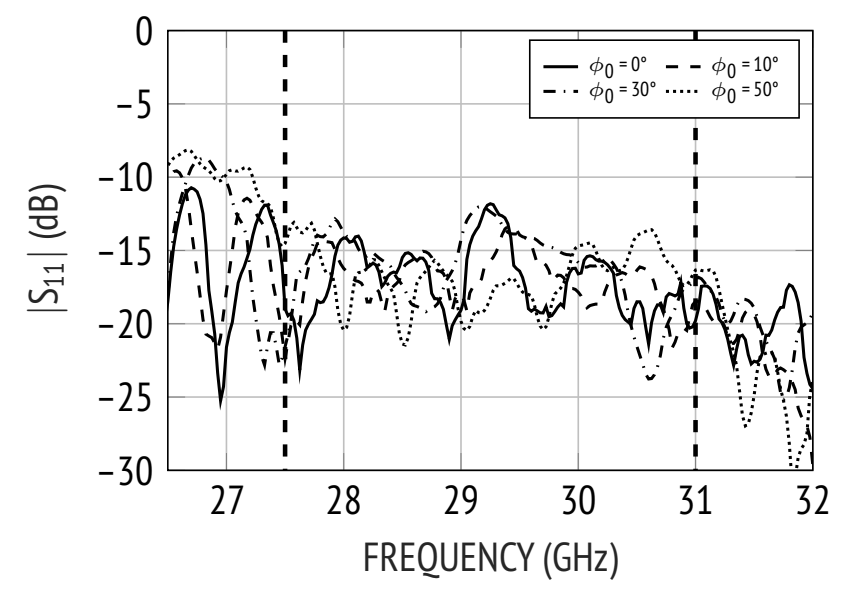

(b)

Fig. 17: (a) Simulated and (b) measured input reflection coefficient for various feed positions.

the increased insertion loss in the gap waveguide, as explained in the previous section.

The $H$-plane radiation patterns of the antenna were measured in the entire uplink Ka-band and are plotted in Fig. 20 for three different feed positions. The scanning angle is stable over the entire frequency range, and the beamwidths have small variation. The worst-case sidelobe levels remain below $-12 \mathrm{~dB}$. As can be seen from Fig. 19, the same pattern stability is achieved also for the other half of the measured feed positions $\left(\phi_{0}<0\right)$.

The peak directiviy extracted from 3D radiation pattern measurements is plotted in Fig. 21 for three different feed positions, showing relatively stable scan losses over the 27.5$31 \mathrm{GHz}$ band. At $29.25 \mathrm{GHz}$, the simulated peak directivity at broadside equals $24.8 \mathrm{~dB}$. An input reflection loss of about $0.15 \mathrm{~dB}$ and conductor losses of 0.3 and $0.25 \mathrm{~dB}$ in the gap waveguide and lens system, respectively, lead to a realized gain of $24.1 \mathrm{~dB}$. It should be noted that the lens insertion loss does not vary significantly with the scanning angle and remains nearly constant over the frequency band of interest. In contrast, the feed network loss varies with frequency and scanning angle, due to the varying effective length of the gap 


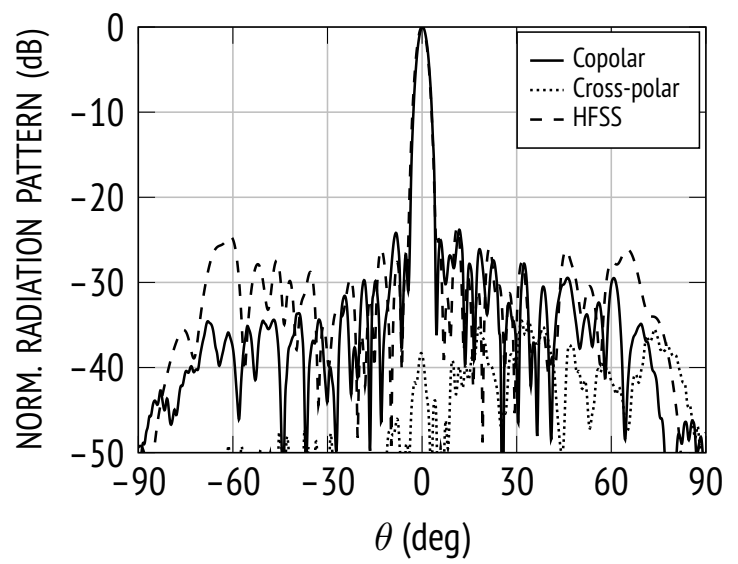

(a)

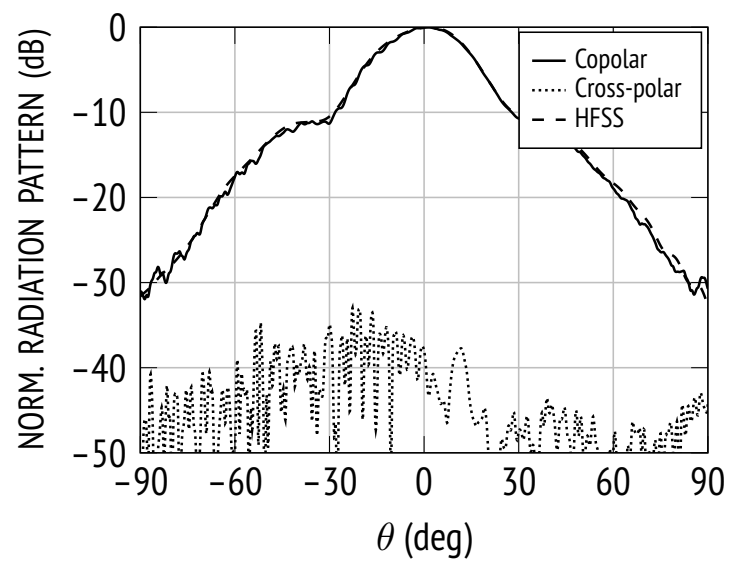

(b)

Fig. 18: Broadside radiation pattern at $29.25 \mathrm{GHz}$ in the (a) $H$ plane, (b) $E$ plane.

waveguide. The estimated worst-case loss is $0.65 \mathrm{~dB}$ ( $\phi_{0}=-$ $50^{\circ}, 27.5 \mathrm{GHz}$ ). This is higher than in fixed-feed designs but in the order of or lower than the insertion loss of Ka-band rotary joints [27], [28], [34]. Within the design band, the estimated radiation efficiency exceeds $78 \%$ for all scan positions.

Considering the lens diameter of $210 \mathrm{~mm}$ and the flare height of $20.5 \mathrm{~mm}$, the simulated broadside directivity of $24.8 \mathrm{~dB}$ at the center frequency corresponds to an aperture efficiency of $60 \%$. The chosen edge taper of $20 \mathrm{~dB}$ accounts for a reduction in efficiency of about $30 \%$. This limitation can be overcome in designs with larger $R / D$ or by introducing a third lens. Simulations confirmed that the remaining difference is attributed to the suboptimal aperture distribution along the $E$-plane, which can be further improved by adjusting the flare angle.

\section{Conclusion AND ReCommendations}

A parallel-plate lens for mechanical wide-angle beam scanning was presented. A dual-lens configuration was introduced to extend the scanning range compared to previous lens designs while maintaining a compact structure. Beam scanning is achieved by rotational movement of a feed system based on the non-contact characteristic of gap waveguides. To validate

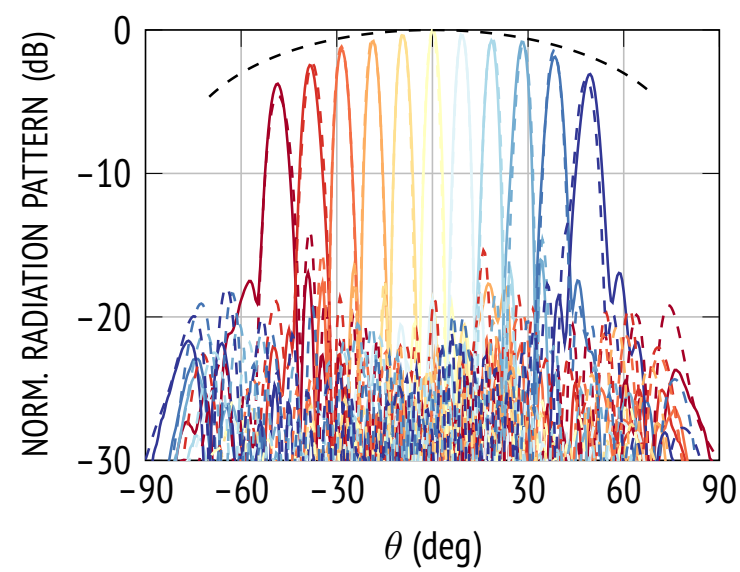

(a)

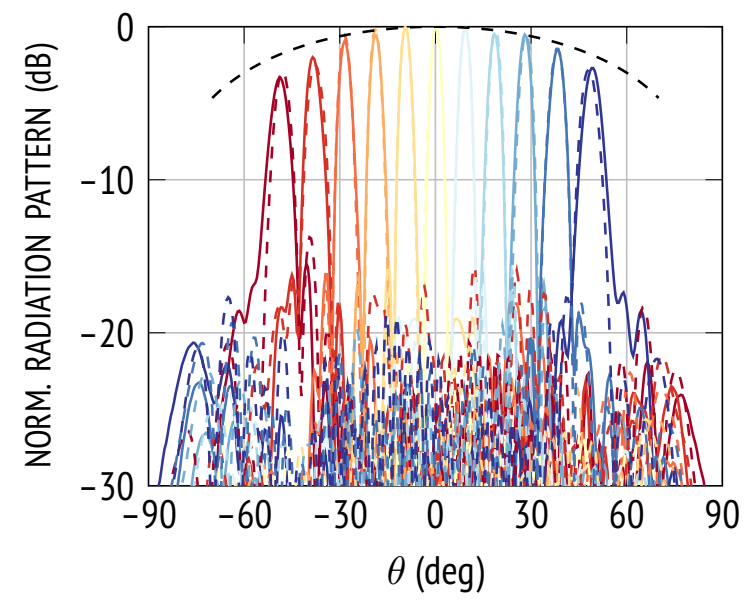

(b)

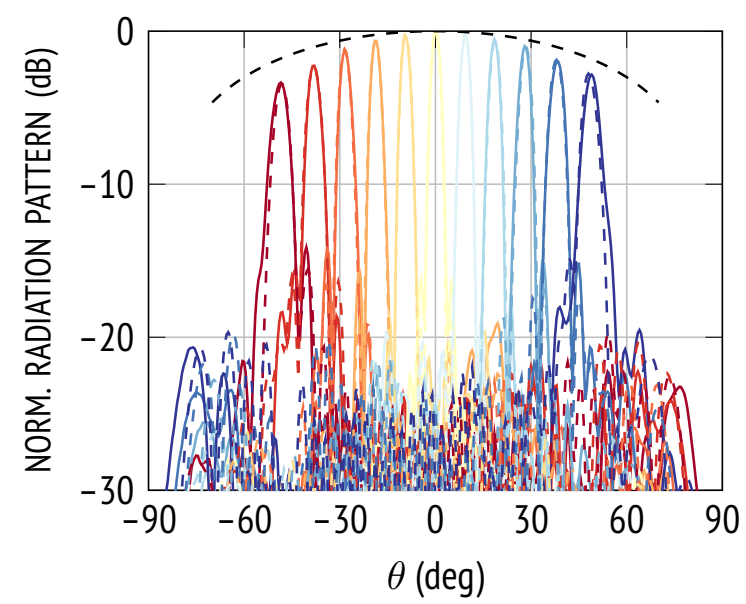

(c)

Fig. 19: Measured (-) and simulated (- -) $H$-plane radiation pattern at (a) $27.5 \mathrm{GHz}$, (b) $29.25 \mathrm{GHz}$ and (c) $31 \mathrm{GHz}$. 


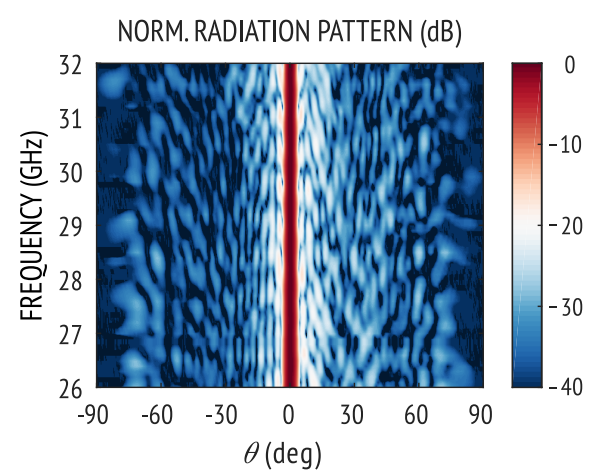

(a) $\phi_{0}=0^{\circ}$

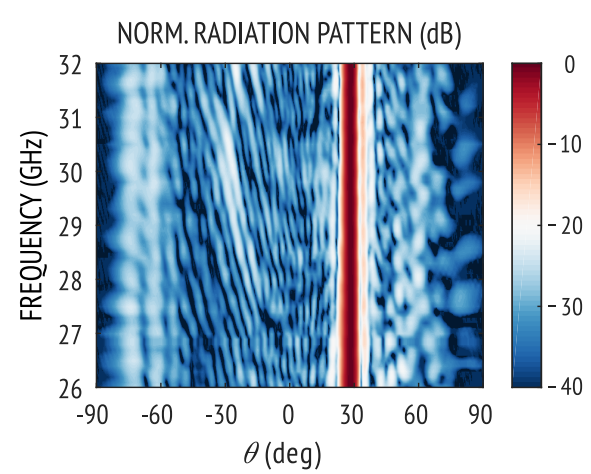

(b) $\phi_{0}=30^{\circ}$

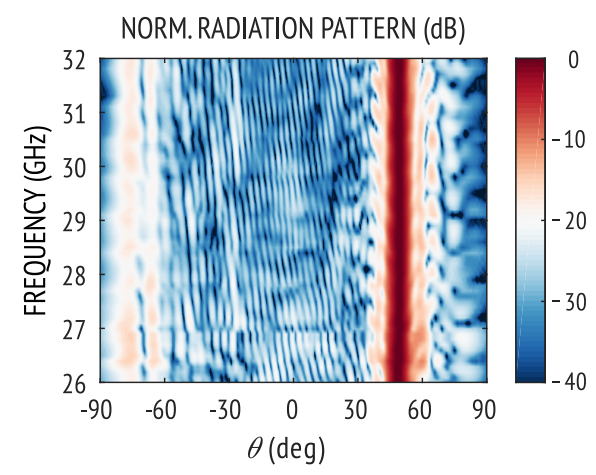

(c) $\phi_{0}=50^{\circ}$

Fig. 20: Measured radiation patterns as a function of frequency and elevation angle for different feed positions.
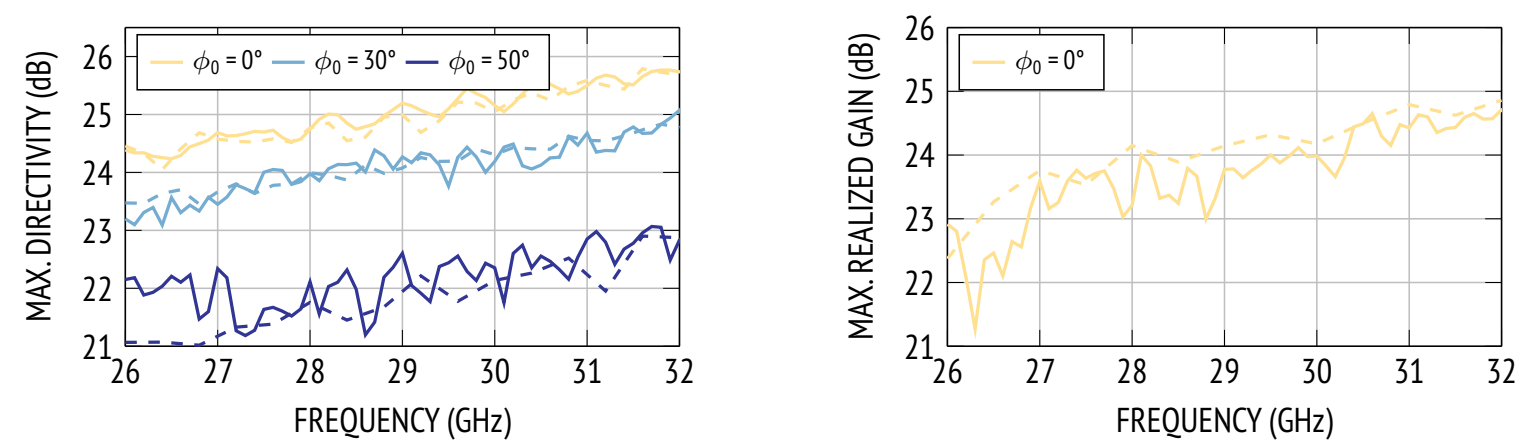

Fig. 21: Measured (-) and simulated (--) maximum directivity and realized gain for selected feed positions.

TABLE I: Comparison of mechanical scanning antenna designs.

\begin{tabular}{|c|c|c|c|c|c|c|c|}
\hline Reference & Type & Impedance bandwidth ${ }^{\mathrm{a}}$ & $\operatorname{Size}^{\mathrm{b}}$ & $\begin{array}{l}\text { Max. } \\
\text { gain }^{b}\end{array}$ & Scan range & $\begin{array}{l}\text { Scan } \\
\operatorname{loss}^{b}\end{array}$ & $\begin{array}{l}\text { Max. } \\
\text { SLL }^{b}\end{array}$ \\
\hline [2] & $\begin{array}{l}\text { Parabolic } \\
\text { pillbox }\end{array}$ & $>26.5-31 \mathrm{GHz}$ & $25 \lambda \times 17 \lambda \times 4.5 \lambda$ & $29 \mathrm{dBi}$ & $\pm 40^{\circ}(7 \mathrm{BW})$ & $2 \mathrm{~dB}$ & $-11 \mathrm{~dB}$ \\
\hline [12] & $\begin{array}{l}\text { Parabolic } \\
\text { pillbox }\end{array}$ & $24-24.5 \mathrm{GHz}$ & $13.5 \lambda \times 15 \lambda \times 0.1 \lambda$ & $22 \mathrm{dBi}$ & $\pm 35^{\circ}(6 \mathrm{BW})$ & $2 \mathrm{~dB}$ & $-12 \mathrm{~dB}$ \\
\hline [16] & $\begin{array}{l}\text { Rotary phase } \\
\text { shifter }\end{array}$ & $75-76.5 \mathrm{GHz}$ & $15.7 \lambda \times 15.7 \lambda \times 6.4 \lambda$ & $34 \mathrm{dBi}$ & $\pm 18^{\circ}$ & $1.3 \mathrm{~dB}$ & $-13 \mathrm{~dB}$ \\
\hline [17] & $\begin{array}{l}\text { Rotary phase } \\
\text { shifter }\end{array}$ & $57-65 \mathrm{GHz}$ & $(8.8 \lambda)^{2} \pi \times 1.9 \lambda$ & $29.3 \mathrm{dBi}$ & $\pm 60^{\circ}$ & $4.3 \mathrm{~dB}$ & $-15 \mathrm{~dB}$ \\
\hline$[33]^{\mathrm{c}}$ & $\begin{array}{l}\text { Continuous } \\
\text { PPW lens }\end{array}$ & $>26-33 \mathrm{GHz}$ & $25.4 \lambda \times 21.5 \lambda \times 4.9 \lambda$ & $25.7 \mathrm{dBi}$ & $\pm 35^{\circ}(10 \mathrm{BW})$ & $2.0 \mathrm{~dB}$ & $-17 \mathrm{~dB}$ \\
\hline [35] & $\begin{array}{l}\text { CTS + rotary } \\
\text { line source }\end{array}$ & $15.35-15.75 \mathrm{GHz}$ & n.a. & $31 \mathrm{dBi}$ & $\pm 30^{\circ}(7 \mathrm{BW})$ & $0.5 \mathrm{~dB}$ & $-15.4 \mathrm{~dB}$ \\
\hline [36] & $\begin{array}{c}\text { Modified } \\
\text { Luneburg lens }\end{array}$ & $29.5-32.5 \mathrm{GHz}$ & $\approx 11.5 \lambda \times 10 \lambda \times 0.8 \lambda$ & $15 \mathrm{dBi}$ & $\pm 35^{\circ}$ & $3 \mathrm{~dB}$ & $-10.5 \mathrm{~dB}$ \\
\hline This work & $\begin{array}{l}\text { Continuous } \\
\text { PPW lens }\end{array}$ & $>27.5-31 \mathrm{GHz}$ & $26.7 \lambda \times 15.9 \lambda \times 9.7 \lambda$ & $24 \mathrm{dBi}$ & $\pm 49^{\circ}(14 \mathrm{BW})$ & $2.7 / 3.3 \mathrm{~dB}$ & $-12.2 \mathrm{~dB}$ \\
\hline
\end{tabular}

\footnotetext{
${ }^{a}$ Referring to the frequency range within which the return loss is greater than $10 \mathrm{~dB}$ for all scan positions.

${ }^{\mathrm{b}}$ Referring to the center frequency and/or the pattern in the plane of scan.

${ }^{c}$ Only full-wave simulation results for a lens made of aluminum are considered.
}

the proposed concept, an all-metal antenna operating at Kaband $(27.5-31 \mathrm{GHz})$ was designed, manufactured and tested. The measured return loss is greater than $12 \mathrm{~dB}$ in the frequency band of interest and beyond. At the design frequency, the scan loss is about $2.7 \mathrm{~dB}$ when scanning out to $50^{\circ}$ (14 beamwidths) and sidelobe levels are less than $-12 \mathrm{~dB}$ over the entire scanning range.

The proposed feed system offers a number of desirable features compared to the solutions based on flexible coaxial cables and rotary waveguide joints. The compatibility of the structure with other all-metal parallel-plate beamformers such as pillbox couplers or geodesic lenses will be investigated in the future. Due to its linear aperture, the lens can be used for phasing more advanced radiating structures such as continuous transverse stub arrays. In such a configuration, the footprint required by the quasi-optical system would be utilized more 
effectively as radiating aperture.

A comparison with state-of-the-art mechanical scanning millimeter-wave antennas (see Table I) demonstrates the advances in terms of scanning performance and bandwidth provided by this solution. The proposed beamformer presents an attractive solution for ground-station antennas which will be operated in large numbers to track highly populated LEO constellations.

\section{ACKNOWLEDGEMENT}

The authors wish to thank X. Morvan for his excellent job in constructing the prototype. The authors would also like to thank Dr. Laurent Le Coq for performing the antenna measurements.

\section{REFERENCES}

[1] C. Hua, X. Wu, N. Yang, and W. Wu, "Air-filled parallel-plate cylindrical modified Luneberg lens antenna for multiple-beam scanning at millimeter-wave frequencies," IEEE Trans. Microw. Theory Techn., vol. 61, no. 1, pp. 436-443, Jan. 2013. DOI: 10.1109/TMTT.2012. 2227780 .

[2] M. Ettorre, F. Foglia Manzillo, M. Casaletti, R. Sauleau, L. Le Coq, and N. Capet, "Continuous transverse stub array for Ka-Band applications," IEEE Trans. Antennas Propag., vol. 63, no. 11, pp. 4792-4800, Nov. 2015. DOI: 10.1109/TAP.2015.2479243.

[3] F. Doucet, N. J. G. Fonseca, E. Girard, X. Morvan, L. Le Coq, H. Legay, and R. Sauleau, "Shaped continuous parallel plate delay lens with enhanced scanning performance," IEEE Trans. Antennas Propag., vol. 67, no. 11, pp. 6695-6704, Nov. 2019. DOI: 10.1109/ TAP.2019.2924904.

[4] N. J. G. Fonseca, Q. Liao, and O. Quevedo-Teruel, "Equivalent planar lens ray-tracing model to design modulated geodesic lenses using non-Euclidian transformation optics," IEEE Trans. Antennas Propag., vol. 68 , no. 5, pp. 3410-3422, May 2020. DOI: 10.1109/TAP.2020. 2963948.

[5] M. Ettorre, R. Sauleau, and L. Le Coq, "Multi-beam multi-layer leaky-wave SIW pillbox antenna for millimeter-wave applications," IEEE Trans. Antennas Propag., vol. 59, no. 4, pp. 1093-1100, Apr. 2011. DOI: 10.1109/TAP.2011.2109695.

[6] W. Rotman, "Wide-angle scanning with microwave double-layer pillboxes," IEEE Trans. Antennas Propag., vol. 6, no. 1, pp. 96-105, Jan. 1958. DOI: 10.1109/TAP.1958.1144548.

[7] X. Wu and J.-J. Laurin, "Fan-beam millimeter-wave antenna design based on the cylindrical Luneberg lens," IEEE Trans. Antennas Propag., vol. 55, no. 8, pp. 2147-2156, Aug. 2007.

[8] R. Hamarneh, O. Zetterstrom, and O. Quevedo-Teruel, "Glidesymmetric Luneburg lens using substrate-integrated-holes for 5G communications at Ka-band," in Proc. 14th Eur. Conf. Antennas Propag. (EuCAP), Mar. 2020.

[9] Q. Liao, N. J. G. Fonseca, and O. Quevedo-Teruel, "Compact multibeam fully metallic geodesic Luneburg lens antenna based on non-Euclidean transformation optics," IEEE Trans. Antennas Propag., vol. 66 , no. 12 , pp. $7383-7388$, Dec. 2018. DOI: 10.1109/TAP.2018. 2872766.

[10] H. Legay, S. Tubau, E. Girard, J.-P. Fraysse, R. Chiniard, C. Diallo, R. Sauleau, M. Ettorre, and N. Fonseca, "Multiple beam antenna based on a parallel plate waveguide continuous delay lens beamformer," in Proc. Int. Symp. Antennas Propag., Oct. 2016, pp. 118-119.

[11] J. Ruze, "Wide-angle metal-plate optics," Proc. IRE, vol. 38, no. 1, pp. 53-59, Jan. 1950. DOI: 10.1109/JRPROC.1950.232789.

[12] E. Gandini, M. Ettorre, M. Casaletti, K. Tekkouk, L. Le Coq, and R. Sauleau, "SIW slotted waveguide array with pillbox transition for mechanical beam scanning," IEEE Antennas Wireless Propag. Lett., vol. 11, pp. 1572-1575, 2012. DOI: 10.1109/LAWP.2012.2235057.

[13] W. C. Wilkinson, "Scanning antenna system," U.S. Patent 2576 182, Nov. 27, 1951.

[14] P.-S. Kildal, E. Alfonso, A. Valero-Nogueira, and E. Rajo-Iglesias, "Local metamaterial-based waveguides in gaps between parallel metal plates," IEEE Antennas Wireless Propag. Lett., vol. 8, pp. 84-87, 2009. DOI: 10.1109/LAWP.2008.2011147.
[15] S. Rahiminejad, E. Pucci, V. Vassilev, P.-S. Kildal, S. Haasl, and P. Enoksson, "Polymer gap adapter for contactless, robust, and fast measurements at 220-325 GHz," Jour. Microelectromech. Syst., vol. 25, no. 1, pp. 160-169, Feb. 2016. DoI: 10.1109/JMEMS.2015. 2500277.

[16] H. Kirino and K. Ogawa, "A $76 \mathrm{GHz}$ multi-layered phased array antenna using a non-metal contact metamaterial waveguide," IEEE Trans. Antennas Propag., vol. 60, no. 2, pp. 840-853, Feb. 2012. DOI: 10.1109/TAP.2011.2173112.

[17] K. Tekkouk, J. Hirokawa, R. Sauleau, and M. Ando, "Wideband and large coverage continuous beam steering antenna in the $60-\mathrm{GHz}$ band," IEEE Trans. Antennas Propag., vol. 65, no. 9, pp. 4418-4426, Sep. 2017. DOI: 10.1109/TAP.2017.2723663.

[18] F. Doucet, N. J. G. Fonseca, E. Girard, H. Legay, and R. Sauleau, "Analytical model and study of continuous parallel plate waveguide lens-like multiple-beam antennas," IEEE Trans. Antennas Propag., vol. 66, no. 9, pp. 4426-4436, Sep. 2018. DOI: 10.1109/TAP.2018. 2846768.

[19] J. Dong, A. I. Zaghloul, and R. Rotman, "Phase-error performance of multi-focal and non-focal two-dimensional Rotman lens designs," IET Microw., Antennas \& Propag., vol. 4, no. 12, pp. 2097-2103, Dec. 2010. DOI: 10.1049/iet-map.2009.0565.

[20] F. Doucet, N. J. G. Fonseca, E. Girard, H. Legay, and R. Sauleau, "Comparison of optimization procedures for the design of continuous parallel plate waveguide multiple beam lens antennas," in Proc. 12th Eur. Conf. Antennas Propag. (EuCAP), Apr. 2018.

[21] W. Rotman and R. Turner, "Wide-angle microwave lens for line source applications," IEEE Trans. Antennas Propag., vol. 11, no. 6, pp. 623-632, Nov. 1963. DOI: 10.1109/TAP.1963.1138114.

[22] N. J. G. Fonseca, "A focal curve design method for Rotman lenses with wider angular scanning range," IEEE Antennas Wireless Propag. Lett., vol. 16, pp. 54-57, 2017. DOI: 10.1109/LAWP.2016.2554281.

[23] T. Katagi, S. Mano, and S.-I. Sato, "An improved design method of Rotman lens antennas," IEEE Trans. Antennas Propag., vol. 32, no. 5 , pp. 524-527, May 1984. DOI: 10.1109/TAP.1984.1143353.

[24] M. Born and E. Wolf, Principles of Optics, 7th ed. Cambridge: Cambridge University Press, 1999, pp. 174-175.

[25] K. S. Kunz, "Propagation of microwaves between a parallel pair of doubly curved conducting surfaces," Jour. Appl. Phys., vol. 25, no. 5, pp. 642-653, May 1954.

[26] T. Takenoshita, "Primary radiator, phase shifter, and beam scanning antenna," U.S. Patent 6597 322, Jul. 22, 2003.

[27] D. G. D. Mesquita and A. G. Bailey, "A symmetrically excited microwave rotary joint," IEEE Trans. Microw. Theory Techn., vol. 18, no. 9, pp. 654-656, Sep. 1970. DOI: 10.1109/TMTT.1970.1127308.

[28] A. Yevdokymov1, V. Kryzhanovskiy1, V. Pazynin1, and K. Sirenko, "Ka-band waveguide rotary joint," IET Microw., Antennas \& Propag., vol. 7, no. 5, pp. 365-369, May 2013.

[29] M. Tayyab Azim, J. Park, and S.-O. Park, "Contactless linear rotary joint at Ku-Band," IEEE Microw. Wireless Comp. Lett., vol. 29, no. 6 , pp. 373-375, Jun. 2019. DOI: 10.1109/LMWC.2019.2912271.

[30] G. L. Ragan, Microwave Transmission Circuits. New York: McGrawHill, 1948.

[31] M. Ebrahimpouri, A. Algaba Brazalez, L. Manholm, and O. QuevedoTeruel, "Using glide-symmetric holes to reduce leakage between waveguide flanges," IEEE Microw. Wireless Comp. Lett., vol. 28, no. 6, pp. 473-475, 2018. DOI: 10.1109/LMWC.2018.2824563.

[32] B. Pyne, R. Naruse, H. Saito, J. Hirokawa, V. Ravindra, and P. R. Akbar, "Robust contactless noncircular choke flange for wideband waveguide applications," IEEE Trans. Microw. Theory Techn., vol. 67, no. 3, pp. 861-867, Mar. 2019. DOI: 10.1109/TMTT.2018.2884885.

[33] T. Ströber, S. Tubau, H. Legay, E. Girard, G. Goussetis, and M. Ettorre, "Parallel-plate waveguide lens for mechanical beam scanning using gap waveguide feed system," in Proc. 14th Eur. Conf. Antennas Propag. (EuCAP), Mar. 2020.

[34] SPINNER GmbH, 1-channel waveguide rotary joint R 320, datasheet 635732, https://products. spinner-group.com/Downloads/Spinner/ 635732-DS.pdf, Munich, Germany.

[35] X. Lu, S. Gu, X. Wang, H. Liu, and W. Lu, "Beam-scanning continuous transverse stub antenna fed by ridged waveguide slot array," IEEE Antennas Wireless Propag. Lett., vol. 16, pp. 1675-1678, Feb. 2017. DOI: 10.1109/LAWP.2017.2664880.

[36] H. B. Molina, J. G. Marin, and J. Hesselbarth, "Modified planar Luneburg lens millimetre-wave antenna for wide-angle beam scan having feed locations on a straight line," IET Microw., Antennas \& Propag., vol. 11, no. 10, pp. 1462-1468, Aug. 2017. DoI: 10.1049/ietmap.2017.0005. 


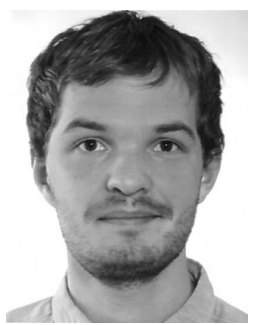

Thomas Ströber was born in Oberndorf bei Salzburg, Austria, in 1993. He received the M.Sc. degree in electrical and computer engineering from the Technical University of Munich (TUM), Munich, Germany, in 2017 and the Ph.D. degree in electrical engineering from the University of Rennes 1 , Rennes, France, and Heriot-Watt University, Edinburgh, United Kingdom, in 2020. His PhD research was part of the doctorate program REVOLVE under the European Commission's H2020 Marie Skłodowska-Curie Actions and carried out in part at the Research and Technologies Department, Thales Alenia Space, Toulouse, France. His current research interests include the analysis and design of quasioptical beamformers, asymptotic high-frequency methods, gap waveguide technology, and conformal metasurfaces.

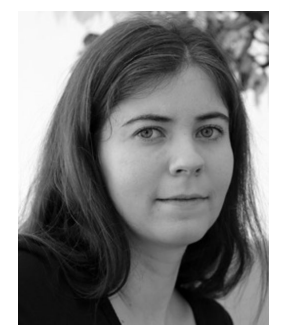

Ségolène Tubau graduated with an electronic engineering degree from the National Institute of Electrical engineering, Electronics, Computer science, Fluid mechanics \& Telecommunications and Networks (ENSEEIHT), Toulouse, France, in 2014 She joined Thales Alenia Space in 2016 after an internship and several interim missions in this company. Her first missions included the study of new concepts of compact feeds and the development of quasi-optical beamformers during the TRP ESA Project "Lens Like Multiple Beam Antenna". Since then, she has been working on the improvement of these concepts which lead to the submission of a new patent in July 2017.

She is now study manager of the ESA ARTES AT 9209 "Array Antenna Generating Multiple Fixed Wide Beams for Low Earth Orbit (LEO) Applications", which focuses on the adaption of quasi-optical beamformer to megaconstellations needs. She is also responsible for the design of the Kineis AIS Antenna and co-supervised.

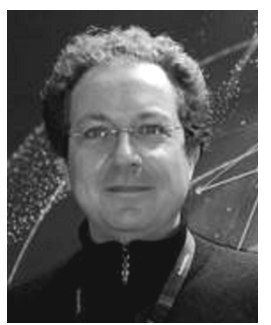

Etienne Girard graduated in 2000 from the INSA engineering school in Rennes with a degree in Electronics and Communications Systems. He received in 2003 a Ph.D. degree in electronics from the IETR, Rennes Institute of Electronics and Telecommunications. From 2003 to 2006 he worked with Alcatel Space in the field of reflectarrays. For 2007 and 2008 he joined Amphenol-JayBeam in Touraine to be part of the development and production of a new base station antenna product line for mobile telecommunications. Since 2008 he is with Thales Alenia Space, contributing to the antenna team in the Research Department. $\mathrm{He}$ has a large range of research interests: MEMS reconfigurable reflectarrays, large antennas for satellite applications, quasi optical beamformers, innovative manufacturing in injection molding, design \& modeling of innovative antenna architectures mixing analog, quasi-optic or digital solutions for an optimal beam forming solution.

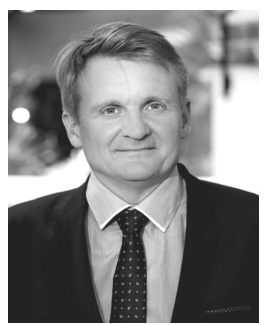

Hervé Legay received the electrical engineering and $\mathrm{Ph} . \mathrm{D}$. degrees from the National Institute of Applied Sciences, Rennes, France, in 1988 and 1991, respectively. He was then a Post-Doctoral Fellow with the University of Manitoba, Winnipeg, MB, Canada.

In 1994, he joined Alcatel Space (now Thales Alenia Space), Toulouse, France. He initially conducted studies in the areas of military telecommunication satellite antennas and antenna processing. He designed the architecture and the antijamming process of the Syracuse 3 active antenna. He is currently the Head of the R\&T on space antennas, developing new antenna concepts with emerging technologies (Reflectarrays, integrated antennas, multiple beam quasi-optical antennas, innovative active architectures, antenna processing,...). He is coDirector of the joint laboratory MERLIN, involving Thales Alenia Space, and the Institut d'Electronique et de Télécommunication de Rennes. Dr. Legay is the Chair of a group of Antenna Experts in Thales Group. He coordinates the collaborations with academic and research partners. He has authored 35 patents. He was a co-prize winner of the 2007 Schelkunoff Prize Paper Award. He was a recipient of the Gold Thales Awards in 2008, a reward for the best innovations in the Thales Group.

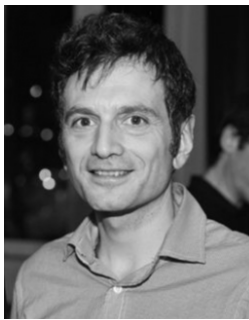

George Goussetis (Senior Member, IEEE) received the Diploma degree in electrical and computer engineering from the National Technical University of Athens, Greece, in 1998, the B.Sc. degree in physics (Hons.) from University College London, U.K., in 2002, and the Ph.D. degree from the University of Westminster, London, U.K., in 2002. In 1998, he joined Space Engineering, Rome, Italy, as an RF Engineer, and as a Research Assistant with the Wireless Communications Research Group, University of Westminster, U.K., in 1999. From 2002 to 2006, he was a Senior Research Fellow with Loughborough University, U.K. He was a Lecturer (Assistant Professor) with Heriot-Watt University, Edinburgh, U.K., from 2006 to 2009, and a Reader (Associate Professor) with Queen's University Belfast, U.K., from 2009 to 2013. In 2013, he joined Heriot-Watt, as a Reader, and was promoted to Professor, in 2014.

He has authored or co-authored over 200 peer-reviewed papers five book chapters one book and two patents. His research interests include the modeling and design of microwave filters, frequency-selective surfaces and periodic structures, leaky wave antennas, microwave sensing and curing as well numerical techniques for electromagnetics. Dr. Goussetis has held a research fellowship with the Onassis Foundation in 2001, a research fellowship with the U.K. Royal Academy of Engineering from 2006 to 2011, and a European Marie-Curie experienced researcher fellowship from 2011 to 2012. He was a co-recipient of the 2011 European Space Agency Young Engineer of the Year Prize, the 2011 EuCAP Best Student Paper Prize, the 2012 EuCAP Best Antenna Theory Paper Prize, and the 2016 Bell Labs Prize. 


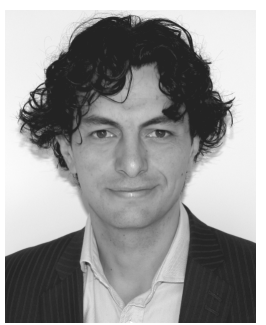

Mauro Ettorre (Senior Member, IEEE) received a Laurea degree "summa cum laude" in Electrical Engineering, and a Ph.D. degree in Electromagnetics from the University of Siena, Italy, in 2004 and 2008, respectively. Part of his Ph.D. work was developed at the Netherlands Organisation for Applied Scientific Research (TNO), The Hague, the Netherlands, where he later worked as an Antenna Researcher. From 2008 to 2010, Dr. Ettorre was a Postdoctoral Fellow at Institut d'Electronique et de Télécommunications de Rennes (IETR), University of Rennes 1, France. In 2010 and 2016, he was a Visiting Scholar in the Radiation Laboratory, Department of Electrical Engineering and Computer Science, University of Michigan, USA. Since October 2010, he is a Research Scientist at the Centre National de la Recherche Scientifique (CNRS), within the IETR. In 2014, he assumed responsibilities for the multi-beam antenna activity for satellite applications in the joint laboratory between IETR and Thales Alenia Space, France. In 2015, he was an Invited Professor at the Tokyo Institute of Technology (TIT), Japan. Since 2017, he is an Associate Editor for the IEEE TRANSACTION ON ANTENNAS AND PROPAGATION. In 2017, 2018 , and 2019 he was a member of the best paper award selection committee for the IEEE TRansactions on Terahertz SCIEnce and Technology. In 2020, he co-founded the open access journal Reviews on Electromagnetics of European Association on Antennas and Propagation (EurAAP) for which he serves as Associate Editor In 2020 and 2021 he was appointed EurAAP ambassador.

Dr. Ettorre's research interests include the analysis and design of leakywave antennas, periodic structures, millimeter-wave antennas, non-diffractive radiation and localized waves, near-field focusing techniques, and wireless power transfer systems.

Dr. Ettorre received the Young Antenna Engineer Prize at the 2008 ESA Antenna Workshop in the Netherlands, the Innovation Award at 2018 ESA Antenna Workshop in the Netherlands, the Best Paper Award in Electromagnetics and Antenna Theory at the 2018 European Conference on Antennas and Propagation (EuCAP), London, UK and the Best Antennas Paper Award at EuCAP 2021, Düsseldorf, Germany. 